\title{
Laws of Radiation From Large Gas Volumes and Claculation of Heat Transfer in Steam Boiler Boxes
}

\author{
A. N. Makarov ${ }^{1}$ \\ ${ }^{1}$ Tver' State Technical University, Russia \\ Correspondence: A. N. Makarov, Tver' State Technical University, Russia. E-mail: tgtu_kafedra_ese@mail.ru
}

Received: November 19, 2014 Accepted: December 8, 2014 Online Published: June 8, 2015

doi: $10.5539 /$ mer.v5n $1 \mathrm{p} 42$

URL: http://dx.doi.org/10.5539/mer.v5n1p42

\begin{abstract}
The progress in the development of methods for calculating heat transfer in torch furnaces, fireboxes, and combustion chambers is analyzed. In the XIX-XX centuries calculations of radiative heat exchange were followed the methods based on the laws of radiation from black body, disclosed in the XVII-XX. It is substantiated that there is crisis of methods for calculating heat transfer in torch furnaces, fire boxes and combustion chambers. In the early XXI century the author of this manuscript disclosed the laws of radiation from torch gas volumes, described in the article.
\end{abstract}

Keywords: laws for radiation, heat exchange, torch, fire box, steam boiler, discovery.

\section{Introduction}

Radiant heat transfer is the main kind of heat transfer and accounts for 90-98\% of the total heat transfer in steam boiler fireboxes (Blokh, Juravlev, \& Ryzkov, 1991), torch heating and melting furnaces (Telegina, 1993; Krivandin \& Egorov, 1989; Makarov \& Svenchanskii, 1992).

Since the late 19th century and throughout the 20th century, heat transfer in torch furnaces, fireboxes, and combustion chambers was calculated based on the law of radiation from black body, particularly on the law, that was experimentally established by Y. Stefan in 1879 in studying radiation from solid bodies, which was then theoretically substantiated by L. Boltzmann in 1884 in studying radiation from solid bodies analytically.

In the late 19th - early20th century, solid lumped fuel (coal, blacks, peat, wood) was fired in furnaces on fire grates, and the first descriptions of heat transfer processes were essentially descriptions of calculation problems of radiant heat transfer between two arbitrarily located hard surfaces (a fuel bed and a heating surface) on the basis of StefanBoltzmann's law.

\section{Retrospective View of Calculation Procedure of Heat Transfer}

The first descriptions of heat transfer processes included bulk fuel burning on fire grates, the only method applied to industrial furnaces, solid fuel furnace. The authors of these descriptions assumed, that burning is completed within fuel bed with overall constant temperature,and gases filling furnace chamber are diathermic and aren't involved in radiative heat exchange between two arbitrarily-spaced surfaces (a fuel bed and a heating surface) using Stefan-Boltzmann law. In 1924, M.V. Kirpichev gave an analysis of methods for solving this problem that had been developed by different researchers (Kirpichev, 1924). Solution of this problem is presently given as follows:

$$
q=c_{S} \varepsilon_{\text {red }}\left[\left(\frac{T_{1}}{100}\right)^{4}-\left(\frac{T_{2}}{100}\right)^{4}\right] \phi_{12}
$$

where $q$ is the density of heat flux radiated from fuel to the heating surface; $c_{s}$ is the black body emis sivity factor; $\varepsilon_{\text {red }}$ is the reduced emissivity; $T_{1}, T_{2}$ are the temperatures of fuel bed and heating surface, respectively; $\phi_{12}$ is the view factor for radiation from the fuel bed on the heating surface.

In 1931, V.N. Shreter also recommended to use Stefan-Boltzmann's law (1) for torch furnaces in the case of firing fuel oil, with the torch was regarded as an isothermal gray body filling the entire space of the chamber (Shreter, 1931). Despite the use of oversimplified assumptions and conceptions about heat transfer processes in chambers that were rather far from reality, the results of calculation carried out for pulverized coal and oil fired furnaces with 
small sizes of the heat absorbing surface and highly extended lining turned to be close to measured results.Subsequent investigations in such furnaces and fireboxes showed how great importane the lining in heat flux flattering and generating dominating radiation from gray solid body is. However, with the advent of waterwall fireboxes, such calculations turned to be unsatisfactory.

In 1932, L.K. Ramzin developed an analytical method for calculating heat transfer that uses the temperature field in the chamber, correlated to a first approximation with the fuel combustion conditions instead the mistaken assumption of constant temperatures in the furnace.

In 1934-1940, V.N. Timofeev continued the works of L.K. Ramzin that proposed to take the torch emissivity equal to the emissivity of triatomic gases contained in it.

The equation for calculating radiation from gas to the wall is presently formulated as follows:

$$
q=c_{S^{2} w{ }^{\varepsilon}} \varepsilon_{\Gamma}\left[\left(\frac{T_{\mathrm{g}}}{100}\right)^{4}-\left(\frac{T}{100}\right)^{4}\right],
$$

where $\varepsilon_{e w}$ - effective emissivity factor (emissivity) of the wall; $\varepsilon_{\mathrm{g}}$ - emissivity factor (emissivity) of gas; $T g, T_{w}$ -gas and wall temperatures respectively. In order to calculate gas radiation to the heating surface by equation (2), gas emissivity must be known. Basic sources of radiation from nonluminous torch are triatomic gases $\mathrm{CO}_{2}$ and $\mathrm{H}_{2} \mathrm{O}$. Radiation of triatomic gases is selective, that is gases radiate and absorb heat energy in the wavelength range, aligned in multispectral regions. Many experiments were carried out on determining the absorption and emission bands for gas and it should be noted, that different researchers obtained different data (Nevskii, 1971). This may possibly be attributed to the fact, that the width of the bands depends on the gas temperature, and beside that, as the gas layer thickness increases, the radiation from spectrum regions with low emissivity is amplified in the neighborhood with radiating bands (Shreter, 1931).

Schack was the first, who attempted to develop a method for calculating emissivity factors of $\mathrm{CO}_{2}$ and $\mathrm{H}_{2} \mathrm{O}$ in 1933 (Shreter, 1931). Design formulas deduced by Shack turned out to be cumbersome and not suitable for account. The difficulties involved with developing analytical methods for calculation emissivity factors of $\mathrm{CO}_{2}$ and $\mathrm{H}_{2} \mathrm{O}$ made many researchers follow the course of graphical calculations. Egbert and Houttel nomograms, plotted in 1939-42, received widespread use. The graphs are presented in two basic diagrams, connected emissivity factors $\mathrm{CO}_{2}$ and $\mathrm{H}_{2} \mathrm{O}$ with temperature and absorbing power on semilogarithmic ccordinates (Shreter, 1931).

Experimental findings of Barr, Fishenden, Houttel ,Egbert, Mangelsdorf, Eckert and other researchers (Mitor, 1963; Blokh, 1984; Nevskii, 1963) for emissivity factors $\mathrm{CO}_{2}$ and $\mathrm{H}_{2} \mathrm{O}$ are conflicting, the difference in results are from 5 to $70 \%$. Eckert data departure from Houttel and Mangelsdorf data by $15-50 \%$. Houttel and Eckert don't offer a satisfactory explanation for the reasons, caused such significant experimental data gaps.

In 1947-1952, specialists of the All Union (presently All Russia) Thermal Engineering Institute (ARTEI) carried out the work aimed at analyzing all these investigations for selecting the most reliable results with a view to construct the calculated radiation graphs for $\mathrm{CO}_{2}$ and $\mathrm{H}_{2} \mathrm{O}$. In 1952, graphs for carbon dioxide and steam emissivity factors were constructed on the basis of these data in standard method for thermal design of boiler unit (ND, 1952).

The gas temperature is plotted on the abscissa ,the emissivity factor is plotted on the ordinate versus the reduced beam lengths $x_{r e d}=p l$. Updated and specified uniform time standards of thermal design for boiler units were published in 1957, 1973, 1998 (Energiya, 1973; ND, 1998).

Method for calculating gas self- radiation and gas radiation on the heating surfaces, created in the $50-\mathrm{s}$ of 1910 had took the complete form by 1960, and during the subsequent years was developed, but hasn't changed significantly.

\section{Modern Methods for Calculating Radiant Heat Transfer}

The range of modern methods for calculating radiant heat transfer is fairly wide, starting from calculations at the microlevel of photon emissions by atoms and ending with obtaining a macropattern of radiation in large objects. In calculations of radiation in the microworld, the molecular kinetic theory of elementary radiation processes is developed, and with regard of macroworld, the theory of radiation in process macrosystems is being sophisticated. The theory of radiant heat transfer in fireboxes, furnaces, and combustion chambers is a theory of radiating technological macrosystems, in which the radiation in microlevel objects and in the macrosystem as a whole has to be calculated. 
Let us consider modern methods for calculating radiative heat transfer. The Monte-Carlo statistical modeling method is based on object physical model, on the use of homogeneous Markov chains (Blokh, Juravlev, \& Ryzkov, 1991). It is applicable for solving transfer integrable equations as well. The Monte-Carlo method enables us to bring the amount of simulated photons into millions or more for maximum object approach. Complex radiating volumes, the distribution of thermogas dynamic parameters by them can be modeled, applying the Monte-Carlo method. However, because this method is numerical, it doesn't allow us to obtain analytic dependences correlating radiant fluxes and the data given even for unsophisticated physical models.

The Shwartzshild-Shuter and Eddington method for solving transfer equations is available for short-cut, evaluative calculations owing to averaging of directional intensity, assumption of isotropic dissipation and isothermality of medium and low accuracy of calculations. The use of the Shwartzshild-Shuter method is justified in research on the effect of the parameters and pattern of disperse systems heat radiation at the level of preliminary, qualitative estimates.

The iteration method of Chandrasekar (Chandrasekar, 1993), Nobel Prize winner in physics of 1983, allows to calculate integral and angular parameters of radiation for nonisothermal areas with any distribution of radiative properties by volume and different boundary conditions, for this reason the method has found a wide utility. However, the disadvantages of the method lie in complexity realizations for non-one-dimensional geometry and iteration of computational process in solving finite difference set of equations. Further development of the discrete coordinate method in two-dimensional geometry is iterative method of characteristics, or Vladimirov's method. It is commonly of high precision (more precisely than Carlson method), particularly at heavy optical thickness. The main weakness of this method is spatial checkout fixation, a variety of quadrature formula coefficients, that makes multidimensional problem calculations difficult (Adzeriho, 1975).

The routine method for solving transport equation is the spherical harmonics method, which numerical solution allows to approximate step by step integro- differential equations system by finitely difference equations, followed by matrix isolating technique. In work (Smelov, 1972) it is underlined, that calculation using the matrix factorization method doesn't lead us to round-off accumulation and being stable.

The method of zonal mathematical modeling has received the widest use for calculations of heat transfer in steam boiler boxes.

The basic idea of the zonal method is that the radiating surfaces and gas volumes are subdivided into zones, and that the continuous distributions of temperatures and physical characteristics are replaced by their piecewise continuous approximations consisting of a finite number of radiating macrosystems, homogeneous zones. In consequence of this, the integral-differential equations describing radiant heat transfer are replaced by an approximating system of algebraic equations, and the sought temperatures of zones and heat fluxes between them are determined by solving this system of equations:

$$
\begin{gathered}
\sum_{i=1}^{m+n} a_{i j} T_{i}^{4}+\sum_{i=1}^{m^{\prime}} V_{i j} c_{i} t_{i}-c_{j} t_{j} \sum_{i=1}^{m} V_{j l}+\sum_{i=1}^{n^{\prime}} \alpha_{k i j} F_{i j}\left(t_{i}-t_{j}\right)+\sum_{r} V_{o j r} c_{o r} t_{o r}=0, \\
j=1 \div m \\
\sum_{i=1}^{m+n} a_{i j} T_{i j}^{4}+\sum_{i=1}^{n^{\prime}} \alpha_{k i j} F_{i j}\left(t_{i}-t_{j}\right)+k_{i} F_{j}\left(t_{n}-t_{j}\right), j=1 \div n
\end{gathered}
$$

where $a_{i j}$ - is the radiation heat-transfer coefficient; $m, n, m^{\prime}, n^{\prime}$-the number of volume and surface and neighboring zones respectively; $V_{i j}$ - the torch intensity from the $i$-th to the $j$-tha zone ; $c_{o r}, c_{i}$ - the heat capacity; $\alpha_{k i j}$ - the heat transfer coefficient by convection; $F_{i j}$ - the contact area of volume - surface zones; $V_{o j r}-$ the actuiating flow to the $j$-th zone.; $k_{j}$ - the heat transfer coefficient; $F_{j}$ - zone area; $T_{i}, t_{n}$ - the temperature.

\section{Calculation of Heat Transfer in a Steam Boiler Box by the Zonal Method}

In Blokh, Juravlev, and Ryzkov (1991) heat transfer is calculated by the zonal method taking as an example the BKZ-320-140 PT steam boiler box. Furnace space was subdivided into 7 calculated tiers, 14 volume and 40 surface zones. Fig 1 , a shows a schematic design of the furnace, Figure 1,b presents distribution of incident radiant fluxes at vertical symmetry axis of the front wall calculated using the zonal method. 


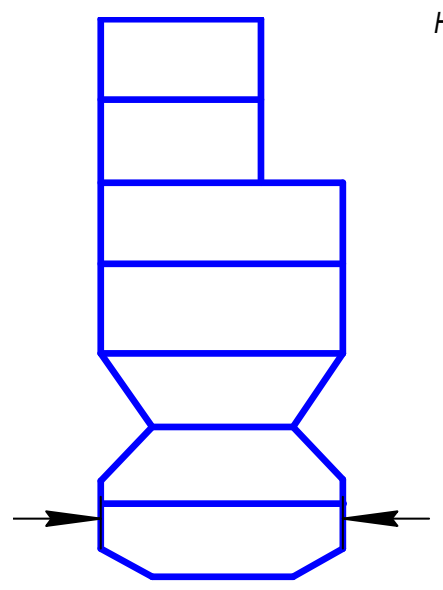

a

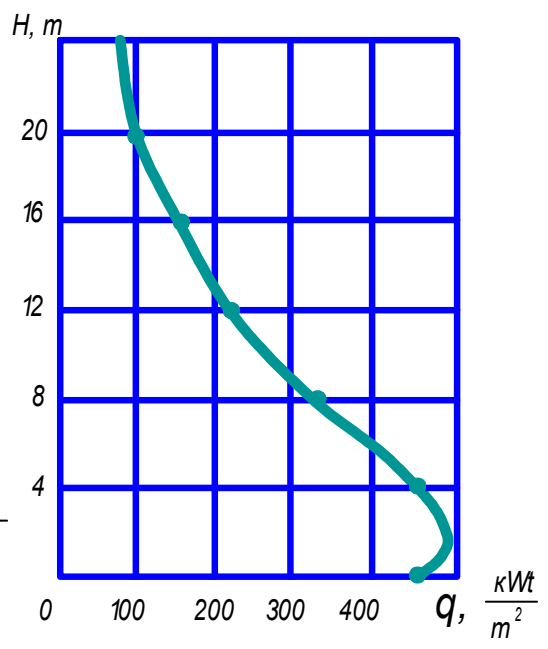

$b$

Figure 1. Subdivision of steam boiler box into calculated tiers (a) and distribution of incident radiation fluxes along the front waterwall axis (b)

The arrangement of burners in the furnace is arrowed in Figure 1,a. The maximal heat fluxes falling on the waterwall surfaces are observed in the area of the burners and account for about $500 \mathrm{~kW} / \mathrm{m}^{2}$.

Radiation fluxes falling from the torch decrease along the furnace height to $230 \mathrm{~kW} / \mathrm{m}^{2}$ at a height of $12 \mathrm{~m}$ and to $75 \mathrm{~kW} / \mathrm{m}^{2}$ in the underceilng zone of the furnace.

The calculated results of distribution for heat fluxes on the front wall vertical symmetry axis are experimentally confirmed.

The difference between heat fluxes along the front wall height obtained by calculation and by measurements reaches 15-20\% (Blokh, Juravlev, \& Ryzkov, 1991).

\section{Crisis of the Existing Methods for Calculating Heat Transfer in Torch Furnaces, Fireboxes, and Combustion Chambers}

Despite the fact that the zonal method has been constantly improved for the last 50 years and has been an engineering calculation method, it still has certain shortcomings:

- The differential and algebraic equations are not analytical expressions which crown the development of any theory if it is possible to solve differential equations;

- In calculating radiation from gas, Stefan-Boltzmann's law is used, which was derived for calculating radiation from solid bodies;

-Radiation and absorption from macrolevel systems, volume and surface zones are calculated, whereas radiation in microlevel systems, radiating particles, and elementary (infinitesimal) radiating volumes is not taken into account;

- The volume radiation from the gas that fills fireboxes, furnaces and combustion chambers is replaced in calculations by surface radiation.

The zonal method for calculating heat transfer in torch furnaces and fireboxes that is based on Stefan-Boltzmann's law does not allow to reveal the distribution of heat fluxes over all heating surfaces.

The zonal method was used to calculate the distribution of radiant heat flux in the steam boiler firebox chambers over the frontal wall height along the wall's vertical symmetry (Blokh, Juravlev, \& Ryzkov, 1991; Blokh, Juravlev, \& Ryzkov, 1991; Alekhnovich, 2007). No data were available on calculating the density of radiant heat fluxes over the perimeter and height of the frontal and lateral walls, and at the periphery of the walls of steam boiler fireboxes. An analysis of the distribution for radiant flux densities over the wall perimeters and heights observed during the operation of steam boiler fireboxes showed, that this distribution has a significantly nonuniform pattern (Makarov, 2012a). 
Modern science is not a dogma, and obvious need arose to use a fundamentally approach to solving the problem of heat transfer in steam boiler boxes.

At the IV Minsk International Forum on heat-mass exchange (MIF-2000), the existing radiative heat exchange design procedure in furnaces, fire boxes with gaseous ,fuel, pulverized flame that flame is simulated by equivalent gas hemisphere, isothermal volume or bulk bands with $i$ - parameters were criticized in series of reports (Germann, 2000).

At the I International Symposium on radiant heat exchange in 1995 it was noted, that there isn't sufficiently safe and effective radiative heat exchange procedure, every existing method has its imperfection and restricted range of application(Germann, 2000).It is concluded in (Germann, 2000), that configuration of radiating gas volume and radiant heat absorbing surface of furnace chamber are disregarded explicitly in the existing method for calculating radiative heat transfer in furnaces and fireboxes. The size, pattern of the radiating volume exert significant determining influence on heat transfer between the heating surfaces.

Radiating rectangular parallepiped, sphere, cylinder follow different laws for radiation and the accuracy of radiative heat transfer calculations in furnaces, fireboxes, combustion chambers is influenced on which set of volume bodies the torch will be modeled. Torch burner length may be different, the torch may be directed to the heating surfaces at different angle, different results of heating can be obtained when it depends on these geometrical parameters of the constant torch power. It has been verified experimentally and analytically, that the determining influence on radiative heat transfer in furnaces and fireboxes exert the torch length and the relative positions of the torch and the heating surfaces (Kutateladze, 1990).

By now, quite a number of facts have been revealed that point to the need of adjusting the existing methods for calculating radiative heat transfer in torch furnaces,fireboxes, and combustion chambers.

Gaseous radiation is characterized by a slightly less dependence from temperature than radiation from gray solid bodies . Radiation from carbonic acid vapour is proportional to the 3.5 power of the temperature, a water vapour radiation is proportional to the third power of the temperature (Kutateladze, 1990). For simplicity, in practical calculations we assume, by convention, that gas radiation is in proportion to its fourth temperature with presenting temperature corrections to the gas emissivity factors (Kutateladze, 1990).

Rise in torch temperature without increase in its power doesn't lead us to the development of furnace capacity. The determining influence on the incident radiation flux densities from the torch on the heating surfaces exerts it's power rather than temperature. At the same temperature of the torch and different power releasing in it, the radiation fluxes falling on the heating surface and the resulting fluxes will be different.The distribution of incident radiation fluxes on the heating surfaces depends on the distribution of power along the torch length.

The torch power can be increased by heating the air supplied. For example, with air heated to $600^{\circ} \mathrm{C}$, the torch power increased by $17 \%$, and its temperature rose from $1300^{\circ} \mathrm{C}$ to $2000^{\circ} \mathrm{C}$, i.e., by a factor of 1.5 (Kutateladze, 1990). According to expression (2), the density of total heat flux from the torch to the calculated zone should increase by a factor of 5 , and the heating rate should also increase by a factor of 5 , which is in contradiction with the energy conservation law. Under the real conditions of heating furnace operation, with air subjected to preheating and with the torch power increased by $17 \%$, the heat flux density and the heating rate increase by $12-$ $15 \%$, i.e., in direct proportion to the growth of torch power and not to the fourth power of temperature (Kutateladze, 1990).

The use of zonal method for torch modeling by rectangular parallepipeds or radiant areas and determination of the total radiation fluxes on the heating surfaces depending on gas-radiation coefficient and the difference in the fourth power of temperature between parallepipeds, areas, by which a flame is simulated and heating surfaces lead us to quick approximate calculation results. This is because gas structure, geometry, pattern, attitude of a flame and heating surfaces is neglected and Stefan-Boltzmann's law for calculating heat transfer between solid surfaces is used. It must be admitted that path of heat transfer research in furnaces, fire boxes, combustion chambers chosen in 1910-20 investigation and being improved throughout the 20th century has proven to be stalemate.

\section{Laws for Radiation From Large Gas Volumes}

The laws for heat radiation, disclosed in the late 19th - early 20th century, characterize radiation from black bodies, i.e. solid bodies. The fact, that black body radiation is a quartic function of its absolute temperature was first determined experimentally by Stefan in 1879, then theoretically by Boltzmann in 1884 (Stefan-Boltzmann law).

Planck's law (the Nobel prize of 1918) characterizes spectral irradiance distribution of black body along the wavelength in the radiation spectrum against the body temperature. 
Wavelength,at which density of black body radiation attains its maximum value, arises from Wien displacement law (the Nobel prize of 1911).

Kirchhoff's law suggests, that ratio between surface density of real body radiation and absorption body coefficient is equal for all the bodies at the same temperature and equals surface density of black body radiation at the temperature given

According to Lambert's law(1760) the intensity of surface radiation in any direction, making an $\alpha$ angle with the normal to a surface is directly proportional to cosine of the angle:

Absorption and scattering of radiation flux is characterized by Bouguer-Lambert-Beer law, that surface radiation fallout in its passage through unit layer absorber material is in proportion to material attenuation coefficient and beam path length in this layer.

In the 17th-20th centuries in the scientific world there was a good tradition to name the law after the author, discovered it. It is evident nowadays, that the scientific ethic binds the researchers to mention the author's name when they follow his law in their studies. The point of the discovery is thus the following.

Solid fuel, fired on fire grates, was the main type of fuel in the 19th - early 20 century, and calculations of heat transfer, made on the base of black body radiation satisfactorily agreed with the measured data of heat surface temperatures. In the 20th and 21st centuries liquid, gaseous, pulverized fuel was used in furnaces, fire boxes, combustion chambers with the flaring formation of volume radiant body - gas radiative torch of a few $\mathrm{kW}$ to some hundreds, sometimes several thousands MW in one or a score of burners. (Figure 2, Figure 3).

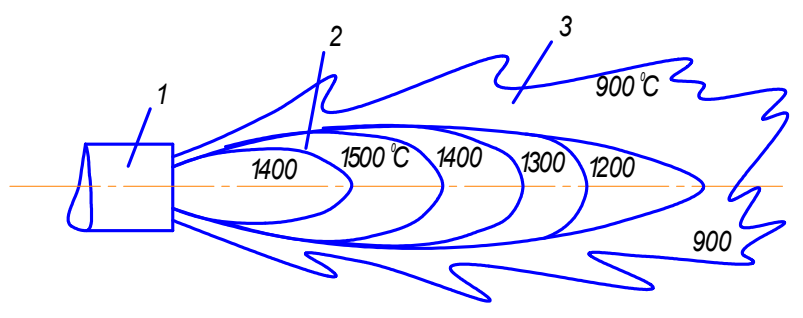

Figure 2. Fuel torch shape and structure with distribution of isotherms over the volume.

1 - burner; 2 - torch; 3 - combustion products

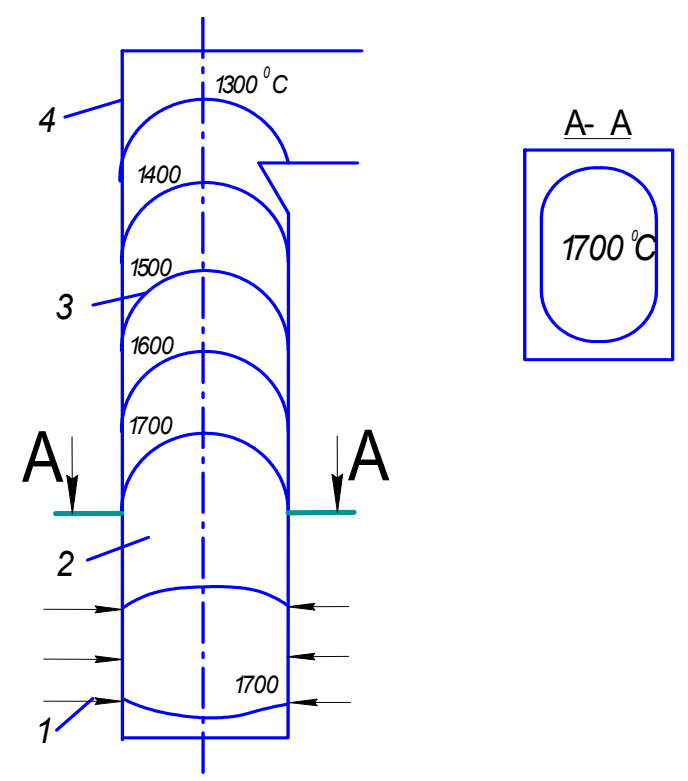

Figure 3. Torch and distribution of isotherms in the steam boiler firebox.

1 - Burner; 2 - firebox; 3 - torch; 4 - waterwall surfaces. 
Laws of blackbody radiation are not applicable to heat transfer calculations of large gas volumes.

In flaring fuel on a single burner, the torch represents gas radiant volume in the form of spheroid of 0,3 to 6 meters in length, with a diameter of major circle from 0,1 to 3,0 meters (Figure 2). Torch, generated by few tens of burners in steam boiler boxes represents gas radiant volume in the form of cylindroids of 10 to 50 meters height (Figure 2), the major axis of ellipse is of 3 to 20 meters in length. Thus, in flaring liquid, gaseous, pulverized fuel, we obtain large radiant gas volumes and in calculating heat transfer, it is necessary to calculate volume radiation rather than surface radiation, considering radiation of a number of gas layers, a number of radiative atoms, gas electrons. For solving this problem, we need triply integrate by gas volume, that is an intricate problem.

The laws of radiation from gas volumes, torch gas layers and electric arc burning in metal vapors of electric arc and plasma arc steel melting furnaces disclosed in 2001 make it possible to calculate volume radiation of torch gas layers to the heating surface. The laws of radiation from torch gas layers were established by the author of this article in 2001 (Makarov, 2003a, 2003b), and during the subsequent decade, this scientific disclosure was verified and approbated, and works were carried out on experimentally confirming and developing the geometrical, physical, and analytic models of torch as a source of heat radiation, and on elaborating the techniques for calculating heat transfer in torch furnaces, fireboxes, and combustion chambers (Makarov \& Dunaev, 2004; Makarov \& Krivnev, 2002; Makarov, 2000; Makarov, Chernyshov, \& Voropaev, 2006; Makarov \& Voropaev, 2004). After carrying out these works, the author of this article filed an application for a scientific disclosure, and in 2011 the relevant patent was granted (Makarov, 2012b).

Radiant heat transfer is common for torch and electric arc furnaces.

The essence of the laws for heat radiation from gas volumes consists in the following. Cylinder gas volumes may be inscribed in gas radiating volumes in the form of ellipsoid and elliptic cylinder, formed in fuel flaring, that is radiation from gas ellipsoid, elliptic cylinder may be approximated by radiation from gas cylinder volumes.

From the laws of radiation from coaxial cylinder gas layers, volumes, radiation from all the layers of large cylinder gas volumes may be equivalently replaced by radiation from central cylinder gas volume of a small diameter. Make certain of justification for these arguments. Let us assume, that isothermal cylinder gas body of 10 meters height, 4.9 meters in diameter is formed in steam boiler box during fuel firing (Figure 4). Let us assume that $18 \mathrm{~kg}$ of fuel oil is burnt in furnace every second and hereby all the $30 \times 10^{30}$ chemical atoms, involving in the combustion process, implicate in photon energy emission. The power of $700 \mathrm{MWth}$, which is steadily distributed along the full cylinder gas volume, releases hourly in a furnace. Let us divide isothermal cylinder radiative and absorbing gas volume by three equal in gas cylinder volume, layers $1-3$. Every layer has equal $10 \times 10^{30}$ atoms. We have calculated angular radiation coefficients, average beam path lengths, radiation fluxes density on $\mathrm{dF}$ calculated platform for every cylinder, layer (Makarov, 2012c, 2012d). As a result of calculations, we have disclosed four laws for heat radiation from isochoric coaxial cylinder gas volumes (Makarov's regularities ) (Makarov, 2014e).

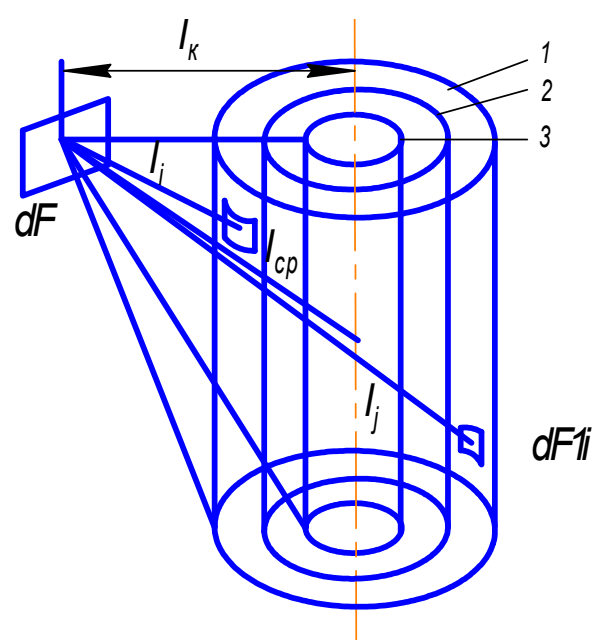

Figure 4. To the calculation of radiant fluxes from coaxial cylinder gas volumes 1-3. $1_{\mathrm{i}}, \mathrm{l}_{\mathrm{j}}, \mathrm{l}_{\mathrm{av}}$ - the distance from $\mathrm{dF}_{1 \mathrm{i}}$ surface elements and arithmetic mean distance to $\mathrm{dF}$ calculated area. 


\subsection{The First Law:}

"Elementary view factors of radiation from coaxial cylindrical gas layers are equal to each other":

$$
\phi_{F_{1} d F}=\phi_{F_{2} d F}=\phi_{F_{3} d F}=\phi_{F_{i} d F}
$$

where $\phi_{F_{1}} d F, \phi_{F_{2}} d F, \phi_{F_{3}} d F, \phi_{F_{i}} d F-$

elementary view factors of radiation from the first, second, third, $i$-th coaxial cylinder layers on the calculated area $d F$.

\subsection{The Second Law:}

"The average path length of beams from coaxial cylindrical gas layers to the calculation area is equal to the arithmetic mean distance from the symmetry axis of cylindrical layers to the calculation area":

$$
l_{\mathrm{av}}=l_{1}=l_{2}=l_{3}=l_{i}=\left(\sum_{j=1}^{n} l_{j} / n\right),
$$

where, $l_{1}, l_{2}, l_{3}, l_{i}, l_{a v}$ - the average beam path length from the first to the $i$ - th cylinder gas layer, respectively, the arithmetic mean distance from the summetry axis to the calculation area $\mathrm{dF}$.

The third law: "The densities of radiation fluxes falling from isochoric coaxial cylindrical gas volumes the calculation area are equal to each other" :

$$
q_{F_{1} d F}=q_{F_{2} d F}=q_{F_{3} d F}=q_{F_{i} d F}
$$

\subsection{The Fourth Law:}

"The total density of radiation fluxes falling on the calculation area from a few radiating and absorbing cylindrical gas volumes (layers) forming the flame is equal to the density of radiation flux from a small diameter coaxial cylindrical gas volume falling on the calculation area at the radiation power releasing in a small diameter cylindrical gas volume and equal to the total radiation power releasing in all coaxial cylindrical gas volumes radiating on the calculation area,"

$$
q_{F_{3} d F}=\sum_{i=1}^{n} q_{F_{i} d F}
$$

\subsection{The Fifth Law:}

"In modeling a flame and an arc by isothermal coaxial cylindrical gas layers and calculating radiative heat transfer, the results of calculations include the volume radiation and absorption in all flame layers and the transfer of heat between them and all heating surfaces."

It follows from five laws of heat radiation, that radiation from isothermal coaxial cylindrical gas volumes is invariant, i.e., the parameters of their radiation, properties are equal to each other.Hence, the radiation from any large gas volume of a high power may be equivalently replaced by radiation from coaxial cylinder gas volumes of a small diameter equal in power. The laws for heat transfer from gas volumes spare us from triple, quadruple integration in radiative heat transfer calculating and make it possible to estimate parameters for radiation from cylinder gas volumes by single integrating of geometric and trigonometric dependences of coaxial cylinder volume of small diameter or, as it is often determined, linear radiation source. Integrating geometrical relations between linear radiation sources and heating surfaces at their any attitude, the author of this article has practically solved the problems of determinating radiation parameters of mentioned bodies and surfaces (Makarov, 2014e).

\section{Calculation of Heat Transfer in the Firebox of a Tgmp-314 Steam Boiler}

Let us calculate heat transfer in the fire box of a TGMP-314 steam boiler with reference to distribution of isotherms and power along the torch height which is the case for opposite arranged burners (Abrutin, Antonov, \& Usman, 1981; Usman, Eniakin, \& Filatov, 1985; Zroichikov, Eniakin, Glusker, 2002). The firebox of a $300 \mathrm{MW}$ power unit has the shape of a rectangular parallelepiped with height $\mathrm{H}_{\mathrm{f}}=35 \mathrm{~m}$, width $\mathrm{a}=14 \mathrm{~m}$, and depth $\mathrm{b}=7 \mathrm{~m}$. The boiler operates on fuel oil and is equipped with 16 burners with a total throughput capacity of $67 \mathrm{t} / \mathrm{h}$, which are installed in opposite directions in two tiers, 8 in each tier at 3 and $6 \mathrm{~m}$ height from the bottom surface (Figure 5). 
The air excess factor in the furnace $\alpha=1.03$, and the gas recirculation ratio $r=0.16$ (Abrutin, Antonov, \& Usman, 1981). With these values of air excess factor and gas recirculation ratio the average values : particle diameter $\mathrm{d}_{\mathrm{p}}=$ $0,278 \mathrm{mcm}$, density $\rho=2 \times 10^{3} \mathrm{~kg} / \mathrm{m}^{3}$, and concentration $\mu=0,06 \mathrm{~g} / \mathrm{m}^{3}$ are determined in Blokh (1984). The medium attenuation coefficient $\mathrm{k}=0,162$.

Figure 5 shows the distribution of isotherms along the height of the TGMP-314 steam boiler box with opposite directed burners.

The torch fills the entire firebox chamber along the firebox height and perimeter and has the shape of a The isotherms divide the straight elliptical cylinder into six volume bodies.

Six volume bodies with ellipses in their bases and vertices and with a parabolic generatrix (the torch vertical parts) have the shape of elliptical paraboloids resting on the seventh volume body having the shape of a truncated ellipsoid of revolution (the horizontal part of torch). Ellipsoid of revolution is spaced in the interior of a truncated ellipsoid, which is formed by isotherm of $1900{ }^{\circ} \mathrm{C}$ in the shape of volume zone with maximal temperature in the firebox of a TGMP-314 steam boiler.

For increasing the calculation accuracy, we inscribe four straight circular cylinders in a torch and simulate it by seven tiers 1-7 of vertical cylinder sources (tier of fours horizontal cylinder sources), and by two tiers 8-9 of horizontal cylinder sources (tier of fours horizontal cylinder sources), while they are spaced in the course of burner axes (Figure 5).

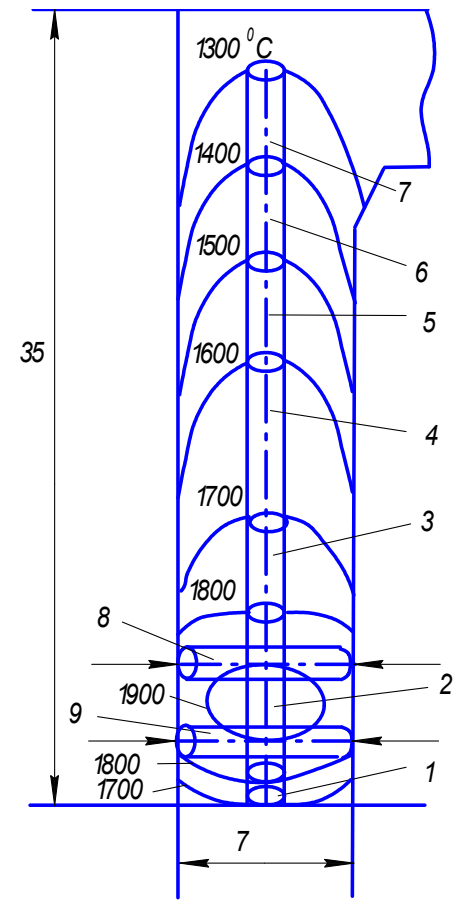

a

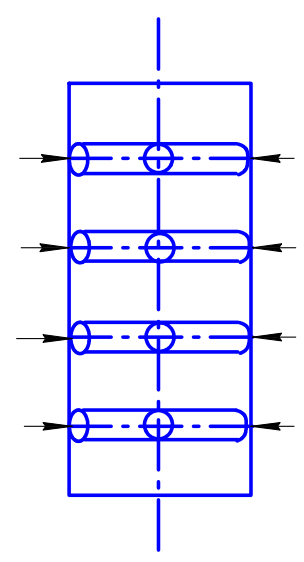

$b$

Figure 5. Distribution of isotherms and cylinder sources of radiation by which flame is simulated in the firebox of a TGMP-314 steam boiler with opposite directed burners

$\mathrm{a}$ - side view; $\mathrm{b}$ - top view; 1-7 - the first -the seventh tiers of vertical cylinder sources, respectively; 8,9 - the eighth and the ninth tiers of horizontal cylinder sources.

The power releasing in the torch is determined from the expression:

$$
P_{f}=Q_{H}^{P} B_{k}
$$

where $Q_{H}^{P}$ is the fuel heating value equal to $41 \mathrm{MJ} / \mathrm{kg}$, and $\mathrm{B}_{\mathrm{k}}$ is the fuel flow rate equal to $67 \mathrm{t} / \mathrm{h} ; \mathrm{P}_{\mathrm{f}}=770 \mathrm{MW}$. 
For calculating the power distribution along the torch height, let us make a proportion which composed of temperatures and zone volumes of the torch. For any flame a proportion for determining the power releasing in each of volume zones may be written:

$$
P_{1}: P_{2}: P_{3} \ldots P_{i}=T_{1}^{3} V_{1}: T_{2}^{3} V_{2}: T_{3}^{3} V_{3} \ldots T_{i}^{3} V_{i}
$$

where $P_{1}-P_{i}$ - the powers releasing in the first- $i$-th volume zones of a torch; $T_{1}-T_{i}$ - the temperatures of the first $-i$-th volume zones respectively.

The product obtained during calculation the proportion (10) torch power fraction, releasing in the torch volume zone into the torch power, gives the heating power, releasing in the volume zone given.

According the Equation (10),we obtained the powers releasing in volume bodies, torch zones and the power, releasing in every linear radiative source of $1-9$ tiers : $P_{I}=15 \mathrm{MW} ; P_{2}=24 \mathrm{MW} ; P_{3}=24 \mathrm{MW} ; P_{4}=31 \mathrm{MW} ; P_{5}=$ $14 \mathrm{MW} ; P_{6}=14 \mathrm{MW} ; P_{7}=7,5 \mathrm{MW} ; P_{8}=33 \mathrm{MW} ; P_{9}=33 \mathrm{MW}$.

In the lower volume zone, restricted by isotherms of $1700{ }^{\circ} \mathrm{C}$ and made up the third part of the firebox space $66 \%$ of torch power is released. In the lower one third part of the firebox space at a distance of 0 to $11 \mathrm{~m}$ over the bottom height $66 \%$ of fuel is burned that causes here the torch power concentration and rise of volume zone with the maximal temperature of $1900 \mathrm{C}$ (Figure 5). It is known, that volume burning velocity increases with the temperature increase and vice versa, with the increase in the volume burning velocity,volume temperature increases that causes the power concentration and high temperatures in the lower volume zone of the firebox. The third height part of torch volume between isotherms of 1700 and $1500{ }^{\circ} \mathrm{C}$, accounts for $23 \%$ of fuel rate and torch power and $11 \%$ of fuel is burning and $11 \%$ of torch power is releasing in the one third higher part of torch volume torch power .

We calculate the incident integral heat flux density from the torch on the following surfaces: on the frontal wall over the wall's vertical symmetry axis; on the frontal wall over the vertical line $4.7 \mathrm{~m}$ off the frontal wall vertical symmetry axis or $2.3 \mathrm{~m}$ off the parallepiped side edge (firebox); on the sidewall along the vertical symmetry axis; on the sidewall along the vertical line $2.0 \mathrm{~m}$ off the sidewall vertical symmetry axis or $1.5 \mathrm{~m}$ off firebox side edge. Calculation of the incident integral radiation flux density from every cylinder source of horizontal and vertical volume zone on the $i$-th wall surface elemental area was made by Equation (Makarov, 2014e):

$$
q_{i n j}=\frac{\phi_{j i} P_{j} e^{-k l}}{F_{i}},
$$

where $\phi_{i j}$ is the local view factor of radiation from the $j$-th cylindrical radiation source on the $i$-th area, which is determined from the analytical expressions given in (Makarov, 2014e); $P_{j}$ is the power of the $j$-th cylindrical source, MW; $F_{i}$ is the surface area of the $i$-th elemental area, $\mathrm{m}^{2}$; and 1 is the average beam path length, $\mathrm{m}$.

The density of incident integral radiation flux from the torch on the $i$ th elemental area is determined as the sum of integral heat flux densities from all cylindrical sources:

$$
q_{i \mathrm{qi} . \mathrm{fl}}=\sum_{j=1}^{36} q_{i n j}
$$

The density of incident integral radiation flux on the $i$ th area caused by reflection of torch radiation from the bottom, ceiling, walls as well as the density of incident integral radiation flux from the radiant surfaces of the bottom, ceiling, walls and convective flux density is not determined due to the fact, that they add up to no more than $5 \%$ of incident integral heat flux density from the torch to the $i$ th elementary area $p$ is determined as the sum of integral heat flux densities from all cylindrical sources if the refractory coat is absent (Makarov, 2014e).

Figure 6 shows the calculation results of incident integral radiation fluxes on the waterwall surfaces of the firebox of a TGMP-314 steam boiler with opposite directed burners.

Graph 2 characterizes the distribution of integral radiation flux density along the frontal wall vertical symmetry axis. In consequence of symmetry of the firebox, it also characterizes the distribution of integral radiation flux density along the rear wall vertical symmetry axis. According the measurement results the distribution of integral radiation fluxes along the frontal and side vertical symmetry axis is the same and is characterized by curve 1 (Abrutin, Antonov, \& Usman, 1981). The measurement results (curve 1) did not vary more than 10 per cent from calculation results along the frontal wall vertical symmetry axis, testifying that the developed firebox of a TGMP-314 steam boiler adequately reflects the real conditions. 
The maximal integral radiation fluxes are observed on the front and rear walls at a height of 12-16 $\mathrm{m}$ (4-5 $\mathrm{m}$ above the top tier of burners). The waterwall surfaces at a height of 12-16 m experience the maximal radiation from the horizontal volume zone and rear walls at a height of 12-16 $\mathrm{m}$ (4-5 $\mathrm{m}$ above the top tier of burners). The waterwall surfaces at a height of 12-16 m experience the maximal radiation from the horizontal volume zone and

Zone of maximum heat release at height of 2-5 $\mathrm{m}$ from the back bottom is characterized by the maximal integral radiation flux densities from the flame to the walls equaled to $680 \mathrm{~kW} / \mathrm{m}^{2}$. Heat release in torch decreases along the torch height, as integral radiation flux densities from the torch decrease on the waterwall surfaces along the wall height.

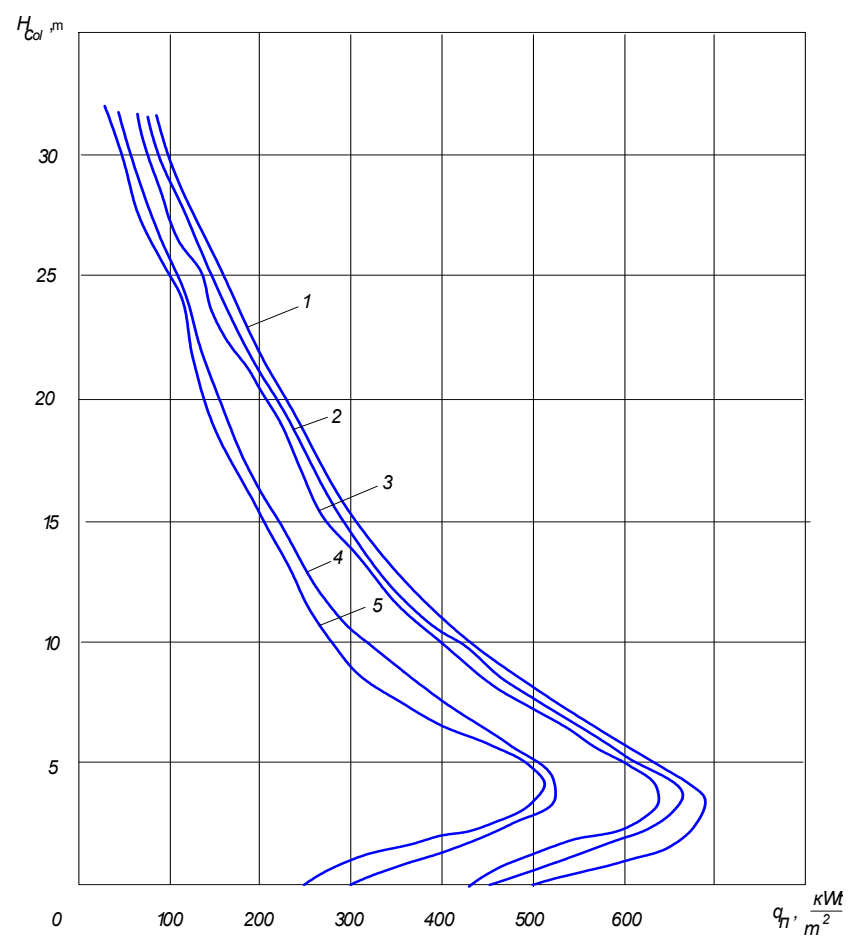

Figure 6. The distribution of integral radiation flux density along the frontal and side wall height of the firebox of a TGMP-314 steam boiler with opposite directed burners

1 - the measurement results of the distribution of integral radiation flux density along the frontal and side walls vertical symmetry axis (Abrutin, Antonov, \& Usman, 1981); 2 - the calculation results of the distribution of integral distribution flux density along the frontal wall vertical symmetry axis ; 3 - the same is along the side wall vertical symmetry axis; 4, 5 - the calculation results of distribution of the integral flux density along the frontal wall vertical symmetry axis ; calculation results of distribution of the integral radiation flux density along the height of lateral wall respectively at a distance of $2 \mathrm{~m}$ from lateral wall vertical symmetry axis and along front wall at a distance of $4.7 \mathrm{~m}$ from front wall vertical symmetry axis.

The surface zone of frontal wall is located at a height of $4.5 \mathrm{~m}$ from the surface bottom opposite the volume zone of the maximal heat release and torch temperature which is characterized by the maximal nonuniformity of integral radiant heat flux densities from the torch (Graph 1). The maximal density of integral radiant flux of $680 \mathrm{~kW} / \mathrm{m}^{2}$ is observed in the center of the waterwall surfaces, the density of integral radiant fluxes decreases by $230 \mathrm{~kW} / \mathrm{m}^{2}$ to the wall periphery. The maximal nonuniformity of integral radiant heat flux densities is observed on the wall surfaces opposite the zone of the maximal heat release from torch: the maximal density of integral radiant heat flux in the center of the frontal wall three times higher than the density of integral radiant heat flux at the periphery of the frontal wall.The distribution of integral radiant flux densities along the lateral wall surfaces are characterized by similar nonuniformity.

It is known, that with increasing the density of incident integral radiation flux on the waterwall surfaces, increases the density of deposits inside the tubes (Davidzon, 2001). 
The nonuniformity of integral radiant heat flux densities along the perimeter decreases at a height of $15-25 \mathrm{~m}$ from the bottom, the difference in the maximal in the center and minimal at the wall periphery densities of integral radiant fluxes_doesn't amount to more than a factor of 2 . The calculated data of distribution of integral radiant heat flux densities along the frontal wall width of steam boiler box with opposite arranged burners agree closely with the results from measurements of deposits inside the tubes.

The deposits are distributed ununiformly over the tube waterwall surfaces: the maximal number are observed in the zone of the largest heat flow near the burners (along the furnace height) and in the center of each wall (Kozlov, Zroichikova, \& Belov, 2003), the minimal - at the furnace wall periphery.

\section{Conclusions}

Thus, theory for radiative heat exchange based on the laws for heat radiation from surfaces of black body radiation is replenished by five laws for heat radiation from gas volumes. The disclosed laws for heat radiation from gas volumes allow us to develope the torch model in the form of radiative gas volume and modern method for calculating heat transfer in torch furnaces, fireboxes. Volume torch pattern, consisted of a set of coaxial radiating and absorbing cylinder gas volumes, layers is used in radiative heat exchange calculation of torch furnaces (Makarov, Chernyshov, \& Voropaev, 2006; Makarov, 2012d), steam boiler boxes (Makarov, 2003; Makarov, 2003; Makarov, 2003; Makarov, \& Voropaev, 2004), combustion chambers of gas-turbine plants (Makarov, Chernyshov, \& Voropaev, 2006; Makarov \& Voropaev, 2004). Calculation results agree closely with measured data of heating fluxes and temperatures in furnaces, fire boxes, combustion chambers (Kozlov, Zroichikova, \& Belov, 2003). The discovery enabled us to design new torch furnaces, fire boxes, combustion chambers. On the basis of disclosed laws for radiation from large gas volumes, it was developed 18 innovative steam boiler boxes, torch heating and electric arc melting furnaces, combustion chambers, ways of heating and melting the metal, providing the improvement in the quality of production, reduction in time of heating and melting the metal, improving the efficiency of plants, decrease in fuel and electric energy consumption, unit pollutant emissions (Makarov, 2012d; Makarov, 2014e; Abrutin, Antonov, \& Usman, 1981; Usman, Eniakin, \& Filatov, 1985; Zroichikov, Eniakin, Glusker, 2002).

The developments are protected by 18 patents (Makarov, \& Shevchenko, 2010; Makarov \& Voropaev, 2012; Makarov, Kruglov, \& Rybakova, 2014a; Makarov, Kruglov, Rybakova, 2014b).

\section{References}

Abrutin, A. A., Antonov, A. Y., \& Usman, Y. M. (1981). Pecularities of heat exchange in powerful oil-fired unit with bottom arrangement of burners. Electricheskiye stancii, 9, 27-30.

Adzeriho, K. S. (1975). Lectures on Radiation transfer theory/ under the editorship of M.A. Elyashevich. Minsk: BSU publishing.

Alekhnovich, A. N. (2007). The thermal efficiency factor of furnace waterwalls as applied to the standard method for thermal calculation of boilers. Therm. Eng., 9, 23-29.

Blokh, A. G. (1984). Heat Transfer in Steam Boiler Fireboxes. Energoatomizdat, Leningrad.

Blokh, A. G., Juravlev, Y. A., \& Ryzkov, L. N. (1991). Radiative heat exchange: Reference. M.: Energoatomizdat.

Chandrasekar, S. (1993). Radiation transfer. M.: IL.

Davidzon, M. I. (2001). The effect of heat flux density on the formation of in tube deposits. Therm. Eng., 1, 72-73.

Energiya, M. (1973). Thermal Design of Boiler Units (a Standard Method) (in Russian).

Germann, M. L. (2000). Engineering method for calculating temperature condition of shell boilers with terminal furnace. In M. L. Herman, V. A. Borodylia, E. F. Nogotov, \& G. I. Palchenok (Eds.), The IV Minsk International Forum on heat-mass exchange (MIF-2000): Proceedings of the Forum.P.2. Radiative and combined heat transfer (pp. 21-31). Minsk: ANK publishing. A.V. Luikov Heat and Mass Transfer Institute of the National Academy of Sciences of Belarus.

Kirpichev, M. V. (1924). About heat transfer in boilers. Usp.Tepl. Tekhn., 2, 17-35.

Kozlov, Y. V., Zroichikova, T. V., \& Belov, V. A. (2003). Ways of improving the reliability of furnace waterwalls. Electricheskiye stancii, 5, 17-19.

Krivandin, V. A., \& Egorov, A. V. (1989). Thermal performance and constructions of iron and steel furnaces: textbook. M.: Metallurgiya.

Kutateladze, S. S. (1990). Heat Transfer and Flow Friction: Handbook. Energoatomizdat, Moscow. (in Russian). 
Makarov, A. N. (2000). Determining the view factors for radiation from a line source and from the fireball of steam boiler furnaces. Therm. Eng., 8, 63-66.

Makarov, A. N. (2003a). Heat-flux distribution in steam boiler box TGMP - 204. Electric Power Plants, 1, 20-25.

Makarov, A. N. (2003b). Heat exchange in electric arc and flame furnaces, steam-boiler boxes: Tutorial, Tver, TSTU.

Makarov, A. N. (2012a). Laws of Heat Transfer for Electric Arc and Torch in Metallurgical Furnaces and Power Installations. TvGTU, Tver (in Russian).

Makarov, A. N. (2012b). A Regular correlation between the parameters characterizing radiation from isothermal coaxial cylindrical gas layers generated during flame combustion of fuel and during the burning of electric arc in metal vapors at atmospheric pressure (Makarov's regularities): A Diploma No. 417. In V. V. Pototskii (Ed.), Scientific Discoveries (RAEN, Moscow, pp. 33-37).

Makarov, A. N. (2012c). Regularities accompanying the burning of electric arc and flame in metallurgical furnaces. Part 1. Geometrical physical and analytical model of flame and arc. Electric Metallurgy, 7, 22-32.

Makarov, A. N. (2012d). Regularities accompanying the burning of electric arc and flame in metallurgical furnaces. Part 2. Use of scientific discovery for decreasing the power consumption in metallurgical furnaces. Electric Metallurgy, 8, 28-35.

Makarov, A. N. (2014e). Regularities of heat transfer in the gas layers of a steam boiler furnace flame. Part II. Gas layer radiation laws and the procedure for calculating heat transfer in furnaces, fire boxes, and combustion chambers developed on the basis of these laws. Thermal Engineering, 61(10), 717-723. http://dx.doi.org/10.1134/S0040601514100073

Makarov, A. N., \& Dunaev, A. Y. (2004). Calculation of heattransfer in a regenerative heating well. Prom. Energ., $1,49-53$.

Makarov, A. N., \& Krivnev, E. I. (2000). Procedure for calculating rational attitude of a flame for Heat transfer optimization in in industrial furnace. Prom. Energ., 2, 36-42.

Makarov, A. N., \& Krivnev, E. I. (2002). Calculation of heatfluxes in the TGMP-204 steam boiler furnace. Prom. Energ., 2, 38-42.

Makarov, A. N., \& Shevchenko, M. N. (2010). A firebox for firing gas-oil fuel. RF Patent No. 2400668 (RU 2400668 C1) F23C3/00, Izobret., No. 27.

Makarov, A. N., \& Svenchanskii, A. D. (1992). Optimum Thermal Conditions of Electric Arc Furnaces. Energoatomisdat,Moscow.

Makarov, A. N., \& Voropaev, V. V. (2004). Simulation of the torch by radiative cylinders and calculation of heat transfer in the TGMP-314 steam boiler furnace. Therm. Eng., 8, 48-52.

Makarov, A. N., \& Voropaev, V. V. (2012). A Regenerative Soaking Pit. RF Patent No. 2457262 (RU 2312907 C1) C21D9/70, Izobret., No. 35.

Makarov, A. N., Chernyshov, D. V., \& Voropaev, V. V. (2006). Calculation of heat transfer in the combustion chamber of a stationary gas turbine unit. Prom. Energ., 1, 31-36.

Makarov, A. N., Kruglov, E. V., \& Rybakova, V. V. (2014a). DC Arc-steel melting furnace. RF Patent No. 2516896 (RU 2312907 C1) C21D9/70, Izobret., No. 35.

Makarov, A. N., Kruglov, E. V., Rybakova, V. V. (2014b). Reheating furnace with ring bottom. RF Patent No. 2517079 (RU 2517079C1) C21D9/70, Izobret., No. 35.

Mastrukov, B. S. (1972). Thermotechnical calculations of industrial furnaces: textbook. Metallurgy, Moscow.

Mitor, V. V. (1963). Heat Exchange in Steam Boiler Boxes. M: Mashgiz.

ND. (1952). Regulations for the Thermal Design of a Boiler Unit. Gosenergoizdat, Moscow, Leningrad (in Russian).

ND. (1998). Thermal Design of Boiler Units (a Standard Method). NPO TsKTI, St. Petersburg (in Russian).

Nevskii, A. S. (1963). Heat Transfer in Open Hearth Furnaces. Metallurgizdat, Moscow (in Russian).

Nevskii, A. S. (1971). Heat Exchange by radiation in Furnaces and Fire Boxes. M: Metallurgiya. 
Pinar Mengus, M. (Ed.) (1995). Radiative Transfer-1. Proceeding of the First International symposium on Radiation Transfer. Kusadasi, Turkey.

Shreter, V. N. (1931). Steam Boilers in Calculations and Figures. Gostekhizdat, Moscow (in Russian).

Smelov, V. V. (1972). Lectures on neutron transfer theory. M.: Atomizdat.

Telegina, A. S. (Ed.) (1993). Heat engineering calculations in metallurgical furnaces: textbook. M.: Metallurgiya.

Usman, Y. M., Eniakin, Y. P., \& Filatov, A. V. (1985). Comparative studies of gas, oil burning and its mixture in the TGMP-314 boiler furnace with bottom arrangement of burners. Electricheskiye stancii, 1, 33-37.

Zroichikov, N. A., Eniakin, Y. P., Glusker, B. N. (2002). Developing the TGMP-314 boilers aided by cyclone primary furnaces for decreasing the irritants and increasing the reliable performance of burner devices and heating surfaces. Therm. Eng., 1, 17-21.

\section{Copyrights}

Copyright for this article is retained by the author(s), with first publication rights granted to the journal.

This is an open-access article distributed under the terms and conditions of the Creative Commons Attribution license (http://creativecommons.org/licenses/by/3.0/). 